\title{
Tissue- and time-dependent estrogen receptor activation in estrogen reporter mice
}

\author{
J G Lemmen', R J Arends ${ }^{2}$, A L van Boxtel'1, P T van der Saag' ${ }^{1}$ and \\ $B$ van der Burg ${ }^{1}$
}

\author{
${ }^{1}$ Hubrecht Laboratory, Netherlands Institute for Developmental Biology, Uppsalalaan 8, 3584 CT Utrecht, The Netherlands \\ 2Department of Pharmacology, NV Organon, Oss, The Netherlands \\ (Requests for offprints should be addressed to P van der Saag; Email: paul @ niob.knaw.nl) \\ (J G Lemmen is now at Laboratory of Reproductive Biology, Juliane Marie Center for Children, Women and Reproduction, University Hospital of \\ Copenhagen, Copenhagen, Denmark) \\ (B van der Burg is now at BioDetection Systems BV, Badhuisweg 3, 1031 CM Amsterdam, The Netherlands)
}

\begin{abstract}
With the aim of developing an in vivo model that directly detects activation of estrogen receptors (ERs), transgenic mice carrying a luciferase reporter gene were generated. The luciferase reporter gene was under the control of three consensus estrogen-responsive elements (EREs) coupled to a minimal TATA-box, with or without flanking chick $\beta$-globin insulators. By using this model in combination with the IVIS imaging system, in vivo ER activation was measured. Dose- and time-dependent luciferase activity was induced in various organs of adult transgenic male mice exposed to diethylstilbestrol (DES) $(10-1000 \mu \mathrm{g} / \mathrm{kg})$ and $17 \beta$-estradiol dipropionate (EP) $(10-1000 \mu \mathrm{g} / \mathrm{kg})$, when luciferase activity was measured ex vivo. The highest ( $>10000$-fold) induction of luciferase was measured in bone and kidney $24 \mathrm{~h}$ after exposure to $1000 \mathrm{\mu g} / \mathrm{kg}$ EP. Other highly responsive organs include liver, testis, pituitary, brain, prostate and colon, which show different activity profiles. This in vivo model for detecting estrogenic activity can be used to assess tissue-specific action of ER agonists and antagonists. These could include selective ER modulators and environmental estrogens. In combination with the IVIS imaging system, this in vivo model is a powerful tool for assessing the kinetics of gene activation by estrogenic compounds.
\end{abstract}

Journal of Molecular Endocrinology (2004) 32, 689-701

\section{Introduction}

Steroidal estrogens exert their physiological actions by activating target genes via estrogen receptor alpha and/or beta (ER $\alpha$ and ER $\beta)$. Estrogens are known to influence numerous target tissues in the female and male reproductive systems, such as mammary gland, uterus, vagina, ovary, testes, epididymis and prostate (Korach et al. 1994). In addition, estrogens have been shown to have a function in bone homeostasis and the central nervous system as well as in the cardiovascular system (Turner et al. 1994, Farhat et al. 1996, Iafrati et al. 1997, LeBlanc et al. 1997).

In addition to physiological steroidal estrogens, a broad number of studies have identified exogenous compounds that exert estrogenic activity. Many of these studies are based on in vitro assays (Grese et al. 1997, Shang \& Brown 2002, Harrington et al. 2003). Such assays basically evaluate ER-binding affinities as well as ER transactivation potential, using various mammalian cell lines and yeast (Andersen et al. 1999, Legler et al. 1999). A common property of these assays is quickness and low cost. However, important aspects for in vivo activity of a compound, such as uptake, distribution, bioavailability and metabolism, are not taken into account in these in vitro assays. Therefore, animal models are necessary to confirm the estrogenic potential of compounds found to be positive in in vitro assays. Two classical in vivo bioassays, the uterotrophic and vaginal cornification assays, have often been used for this purpose. In these 
assays, rodents are exposed to the test compounds, and either the uterus wet weight or the extent of vaginal cornification is assessed (Ashby et al. 2000, Schlumpf et al. 2001). The specific mechanisms underlying these effects are not known and theoretically could be effective without a direct interaction between the compound and the ER. A different approach that is increasingly used as a marker for ER activation is induction of target genes in vivo (Diel et al. 2000, Khurana et al. 2000). However, a drawback of these assays is that target genes are often studied only in no more than one organ or tissue at a time. An in vivo model involving direct detection of activated ERs in a broad range of tissues would combine the advantages of in vivo and in vitro assays.

To develop an in vivo model with direct detection of activated ERs, transgenic mice carrying a luciferase reporter gene under the control of three consensus estrogen-responsive elements (EREs) coupled to a minimal TATA-box (3xERE-TATALuc) were generated. In addition, to improve expression and minimize effects of DNA sequences surrounding the transgene, transgenic mice carrying a similar construct flanked by two copies of the chick $\beta$-globin insulator (Chung et al. 1993, Wang et al. 1997, Potts et al. 2000) were generated. Although other estrogen reporter mice have been generated, these models do not exclude EREindependent activation because of the presence of other promoter sequences (Ciana et al. 2001, Nagel et al. 2001, Toda et al. 2003). The use of only a minimal TATA-box in the construct used in the present study will avoid activation of the construct via other promoter sites than the EREs. Our generated transgenic animals were exposed to $17 \beta$-estradiol $\left(\mathrm{E}_{2}\right), 17 \beta$-estradiol-dipropionate $(\mathrm{EP})$ or diethylstilbestrol (DES) to compare and characterize their ability to activate the reporter construct, luciferase, via endogenous ERs. In addition, to test ER dependency of the luciferase induction, the ER antagonist ICI 182,780 (ICI) was tested alone and in combination with DES. A new in vivo luciferase imaging system (IVIS; Xenogen, Alameda CA, USA) was used to follow the kinetics of luciferase activity in vivo after exposure to the estrogens. The activity of luciferase in a broad range of tissues and organs was measured ex vivo after in vivo exposure to estrogens.

\section{Materials and methods}

\section{Transgenic constructs}

Two estrogen-responsive reporter gene constructs were used (Fig. 1A). One (3xERE-tata-luc), carrying three copies of a consensus ERE and a TATA-box in front of the luciferase cDNA, is described in more detail elsewhere (Legler et al. 1999). The second construct (3xERE-tata-lucinsulated) was made by cloning 3xERE-tata-luc between chicken $\beta$-globin insulators. From the pJC13-1 construct (Chung et al. 1993), the locus control region was removed by EcoRI restriction and self-ligation. Subsequently, the neo cassette was removed by BamHI restriction. The 3xERE-tataluc construct was inserted in the blunted BamHI site of pJC13-1. Transient transfections of the constructs together with ER $\alpha$ in HEK293 cells were performed as described previously (Kuiper et al. 1998).

\section{Generation of transgenic animals}

Female F1 mice from $\mathrm{CBA} \times \mathrm{C} 57 \mathrm{Bl} / 6 \mathrm{~J}$ crosses were superovulated by intraperitoneal (i.p.) injection of pregnant mare serum (5IU) and, $46 \mathrm{~h}$ later, human gonadotropin (5IU). Before zygote injection, constructs were linearized and cleaned by dialysis. DNA was dissolved in injection buffer $(10 \mathrm{mM}$ Tris, $\mathrm{pH} 7 \cdot 6$, and $0 \cdot 1 \mathrm{mM}$ EDTA) to a final concentration of approximately $2 \mathrm{ng} / \mu \mathrm{l}$. Of this, $5 \mathrm{pl}$ were injected into the male pronucleus of one-cell zygote embryos. Injected embryos were cultured in M16 medium until transfer into the oviduct/uterus of $\mathrm{CBA} \times \mathrm{C} 57 \mathrm{Bl} / 6 \mathrm{~J} \mathrm{F1} \mathrm{females} \mathrm{on}$ day 0.5 of pseudopregnancy. After weaning, ear-cut material of the pups was collected, and DNA was isolated as described before (Legler et al. 2000). PGR for detecting reporter construct integration in the mouse genome was performed with primers located within the transgenic construct (Legler et al. 2000). With the 3xERE-tataluc construct, three founders $(\mathrm{A}-\mathrm{C})$ were obtained; with the 3xERE-tata-luc-insulated construct, nine founders (INS1-9) were obtained. Founders were subsequently crossed with C57BL/6J mice to obtain F1 animals. Animals used for estrogen-exposure experiments described were 8-16-week-old male F1 animals from founder INS7. 


\section{Estrogens and in vivo exposure}

17 $\beta$-Estradiol $\left(\mathrm{E}_{2}\right), 17 \beta$-estradiol-dipropionate $(\mathrm{EP})$ and diethylstilbestrol (DES) were all purchased from Sigma-Aldrich (Roosendaal, The Netherlands). ICI 182,780 (ICI) was obtained from Tocris Cookson Ltd (Bristol, UK). Stock solutions of estrogens $(10 \mathrm{mg} / \mathrm{ml})$ and ICI $(25 \mathrm{mg} / \mathrm{ml})$ were prepared in corn oil (Sigma-Aldrich) and were subsequently diluted further to final test concentrations in corn oil. Exposure of transgenic mice was done by i.p. injection. The doses for EP and DES exposure $(10-1000 \mu \mathrm{g} / \mathrm{kg})$ were chosen in order to see the dose response in the IVIS system, which is less sensitive than the in vitro measurements on lysates. ICI was given $1 \mathrm{~h}$ prior to DES in the combination exposure. The numbers of animals for each exposure group are indicated in each figure legend. The mice were maintained under constant conditions with a photoperiod of $12 \mathrm{~h}$ light (beginning at $0700 \mathrm{~h}$ ) and $12 \mathrm{~h}$ darkness. Food and water were supplied, and animals were allowed to feed ad libitum. All animal experiments were done with approval of the Netherlands Academy of Arts and Sciences Animal Ethics Committee (protocol HL01.09 and HL02.15). The IVIS experiments were done with additional approval from the Animal Ethics Committee of NV Organon.

\section{Luciferase measurement in vivo}

With the Xenogen IVIS imaging system, the luciferase protein was monitored in living animals. Animals were injected subcutaneously with the luciferase substrate, luciferin $(100 \mu \mathrm{l}$ of stock $30 \mathrm{mg} / \mathrm{ml}$ in PBS). After $15 \mathrm{~min}$, the animals were placed in a dark imaging chamber under isoflurane anesthesia. Photon emission resulting from the luciferin/luciferase reaction was detected with a sensitive CCD camera. This photon image was superimposed on a normal video image of the mouse with Living Image software (Xenogen). With IGOR software (WaveMetrics Corporation, Lake Oswego, OR, USA), the photon signal was quantified. The number of detected photons correlates with the amount of luciferase protein.

\section{Tissue isolation and in vitro luciferase measurement}

Animals were killed by $\mathrm{CO}_{2} / \mathrm{O}_{2}$ asphyxiation 8 or $24 \mathrm{~h}$ after estrogen exposure. Subsequently, tissues (pituitary, esophagus, testis, brain, colon, adrenal, liver, prostate, small intestine, bone (femur), heart, kidney and lung) were isolated and frozen at $-80{ }^{\circ} \mathrm{C}$. For luciferase analysis, tissues were thawed on ice, and lysis buffer $(1 \%(\mathrm{v} / \mathrm{v})$ Triton X-100, $2.5 \times 10^{-2} \mathrm{M} \quad$ glycylglycine, $1.5 \times 10^{-2} \mathrm{M}$ $\mathrm{MgSO}_{4}, 4 \times 10^{-3} \mathrm{M}$ EGTA and $1 \times 10^{-3} \mathrm{M}$ dithiothreitol (DTT)) was added. The tissues were homogenized with an Eppendorf micropestle, and the lysate was centrifuged and the supernatant collected. Duplicate samples $(25 \mu \mathrm{l})$ were measured for luciferase enzyme activity on a luminometer (LUMAC/3 M BV, Schaesberg, The Netherlands), using $100 \mu \mathrm{l}$ of luciferin substrate solution (33 mM DTT, $20 \mathrm{mM}$ tricine, $1 \mathrm{mM}$ $\left(\mathrm{MgCO}_{3}\right) \mathrm{Mg}(\mathrm{OH})_{2} \cdot 5 \mathrm{H}_{2} \mathrm{O}, \quad 2.67 \mathrm{mM} \quad \mathrm{MgSO}_{4}$, $0.1 \mathrm{mM}$ EDTA, $270 \mu \mathrm{M}$ coenzyme A, $470 \mathrm{mM}$ luciferin and $530 \mu \mathrm{M}$ ATP, pH 7·8). Protein correction was performed after protein measurements using the Biorad (München, Germany) kit according to the manufacturer's instructions.

\section{Statistical analysis}

For the transfection experiments, the EC50 values were calculated by determining the concentration by which $50 \%$ of maximum activity was reached, using the sigmoidal fit equation. The $\mathrm{E}_{2}$ curve was fitted using the sigmoidal fit $(\mathrm{y}=\mathrm{ao}+\mathrm{a} 1 / 1+\exp (-(\mathrm{x}-$ a2)/a3)) in Slidewrite Plus for Windows $3 \cdot 0$, which determines the fitting coefficients by an iterative process minimizing the c2 merit function (leastsquares criterion). For the IVIS experiments, significant differences of treatment groups from oil-exposed controls were determined by KruskalWallis analysis followed by Dunn's post-test. In addition, the presence of a linear trend in the dose response was determined by ANOVA followed by Dunn's post-test for linear trends. For the IVIS time-course experiments, Friedman's test followed by Dunn's post-test was performed. For the luciferase measurements on organ lysates (see Fig. 4) after $\log$ transformation of the data, significant differences between all groups were determined by ANOVA followed by Tukey's post-test. All analyses were carried out with GraphPad Prism 3.02. 
A
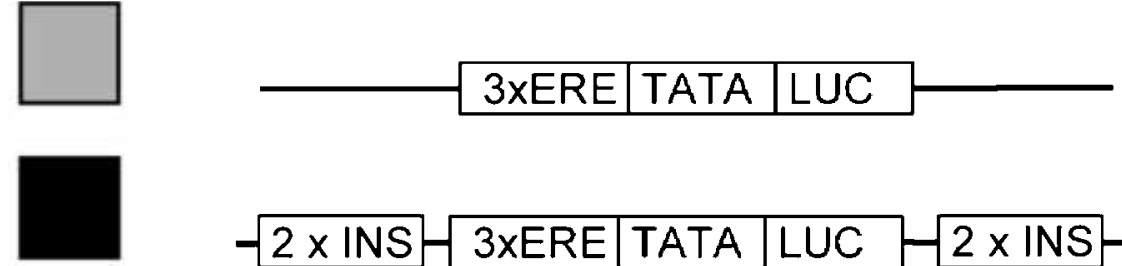

$-2 \times$ INS $3 \times$ ERE TATA LUC $2 \times 1$ INS-

B

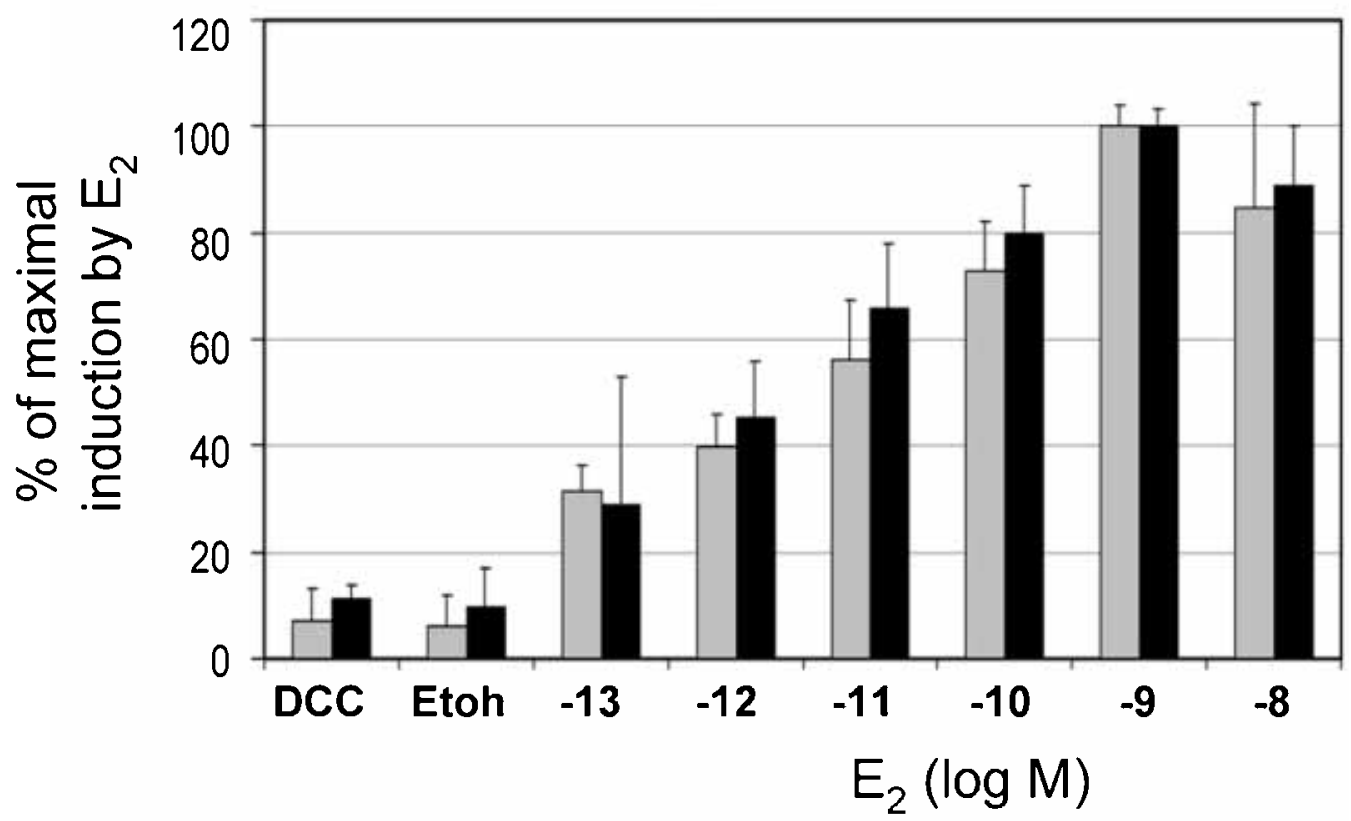

C

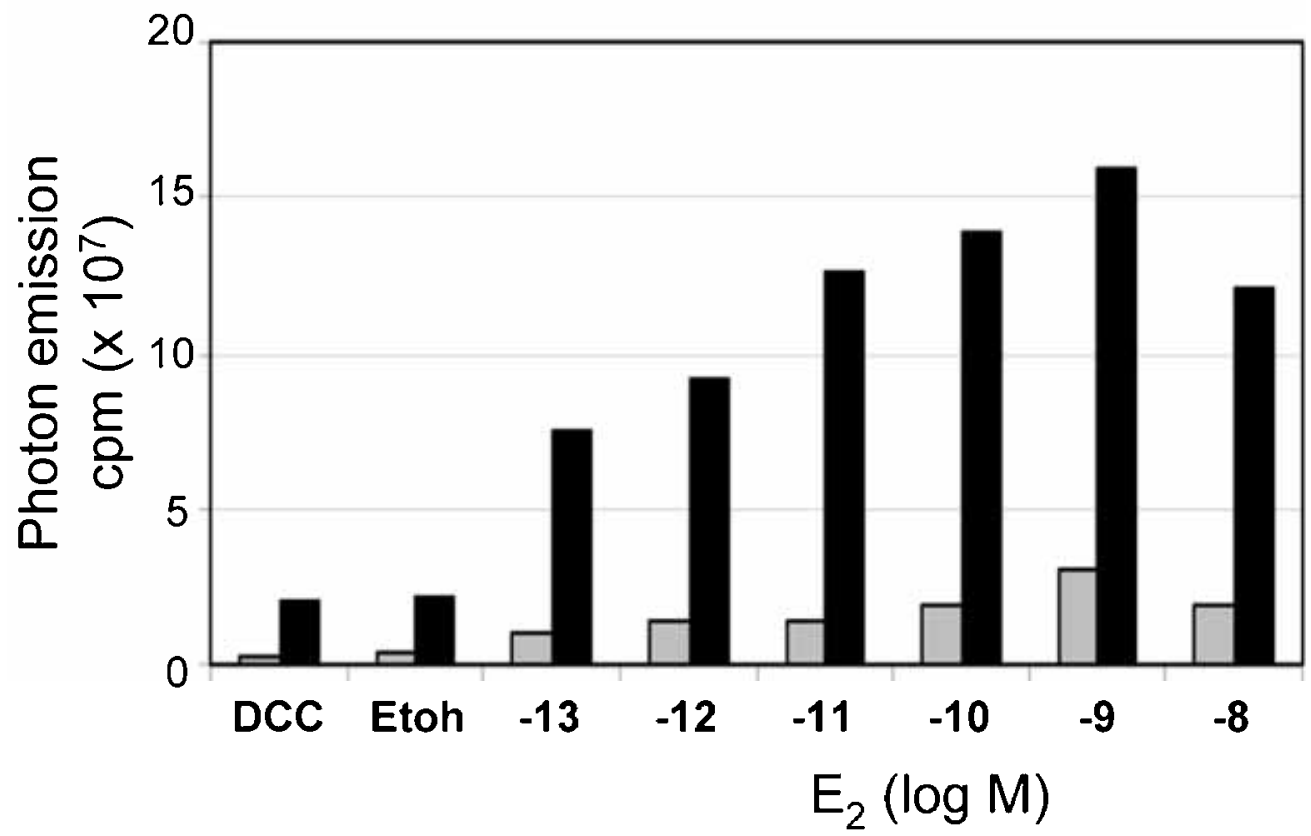




\section{Results}

\section{In vitro comparison of estrogen-responsive reporter constructs}

The newly generated insulated construct (3xERE-tata-luc-insulated; Fig. 1A) was compared with the previously described estrogen-responsive 3xERE-tata-luc construct (Legler et al. 1999) in transient transfection experiments with ER $\alpha$. After $\mathrm{E}_{2}$ exposure of transiently transfected 293 cells, a dose-dependent activation of each construct was observed (Fig. 1B). The dose--response profile was similar for both reporter constructs, reaching maximal induction at $1 \mathrm{nM} \mathrm{E_{2 }}$ (Fig. 1B), whereas total luciferase activity was highest for the insulated construct (Fig. 1C). Fold induction was also higher for the insulated construct, 19.1 times over solvent control in comparison to 13.8 times for the noninsulated construct. The concentrations of $\mathrm{E}_{2}$ needed for half-maximal activation (EC50) of the constructs were $3.8 \times 10^{-12}$ and $1.9 \times 10^{-11} \mathrm{M}$ respectively, for the insulated and noninsulated construct.

\section{Characterization and selection of transgenic lines}

With the 3xERE-tata-luc construct, three founder mice were obtained, lines A, B and C. Nine founder mice were obtained with the 3xERE-tataluc-insulated construct, lines INS1-9. Transgenic lines with germ-line transmission of the constructs were characterized for luciferase induction after DES exposure $(1000 \mu \mathrm{g} / \mathrm{kg})$. With the IVIS system, background luciferase activity was detected in testes of nonexposed animals from lines $\mathrm{C}$ and INS9. This activity was further enhanced by exposure to DES (Table 1). In lines INS3, INS7 and INS9, luciferase activity was observed in the liver only after DES exposure (Table 1). In the paws of animals from lines INS3 and INS7, a constitutive luciferase activity was detected, which was unaltered by DES exposure (Table 1). When luciferase activity was measured in tissue lysates, the tissue distribution of DES-induced luciferase activity was similar in animals from lines INS3 and INS7 (Table 1) and could be detected in a broad range of tissues. After DES exposure, animals from INS9 showed a tissue distribution of luciferase activity partially similar to lines INS3 and INS7, whereas animals from line $\mathrm{C}$ showed expression in liver and testis, and animals from line INS4 and INS5 showed luciferase activity in the liver only (Table 1). Male animals from line INS7 were selected for further experiments due to their high induction of luciferase in various tissues after DES exposure when measured ex vivo. In addition, with the IVIS system, it was possible to follow in vivo activation of luciferase in this line, making its animals suitable for studying kinetics of gene activation by estrogens. Male mice were chosen to avoid having to perform ovariectomy to bring down background levels of circulating estrogens.

\section{Kinetics of luciferase induction measured in vivo after DES and EP exposure}

The advantage of using the IVIS system is that the induction of luciferase in a single animal can be followed in time, making it a very useful tool in

Figure 1 In vitro response of insulated and noninsulated estrogen reporter constructs to $17 \beta$-estradiol $\left(E_{2}\right)$. $(A)$ Schematic illustration of the constructs used for generating transgenic reporter mice. The first construct consists of three consensus estrogen-responsive elements (EREs) from the vitellogenin gene coupled to a minimal TATA-box and luciferase. The second construct is essentially the same, but flanked on both sides by chicken $\beta$-globin insulator sequences. $(B) E_{2}$ activation of the reporter constructs shows a similar dose-dependent induction of luciferase activity, when taken as percentage of maximal induction by $\mathrm{E}_{2}$. Transient transfections were carried out with either construct together with ER $\alpha$ in HEK 293 cells. Cells were exposed to $\mathrm{E}_{2}$ or medium/ethanol controls as indicated. Luciferase activity was measured $24 \mathrm{~h}$ after exposure. Abscissa: log $\mathrm{M}$ of $\mathrm{E}_{2}$, medium alone (DCC) or ethanol (solvent) control. Ordinate: luciferase activity as percentage of maximal induction by $\mathrm{E}_{2}$. Shown is the average of three independent experiments performed in triplicate. (C) Photon emission (c.p.m.) resulting from the luciferin/luciferase reaction was higher when the insulated reporter construct was transfected than with the noninsulated reporter construct. Photon emission correlates with the amount of luciferase protein. Transient transfections and exposure were performed as described under $\mathrm{B}$. Abscissa: $\log \mathrm{M}$ of $\mathrm{E}_{2}$, medium alone (DCC) or ethanol (solvent) control. Ordinate: c.p.m. of photon emission correlating with absolute luciferase protein amounts. Shown is a representative experiment. c.p.m., counts per minute; DCC, medium with dextran-coated, charcoal-stripped serum; $E_{2}, 17 \beta$-estradiol; Etoh, $0.1 \%$ ethanol (solvent) control. 
Table 1 Luciferase activity in transgenic lines with germ-line transmission of ERE-reporter genes

\section{Transgenic lines}

\begin{tabular}{|c|c|c|c|c|c|c|c|c|c|c|c|c|c|}
\hline \multirow[b]{4}{*}{ IVISa } & \multirow[b]{3}{*}{ Background } & \multicolumn{3}{|c|}{$3 \times$ ERE-tata-luc } & \multicolumn{9}{|c|}{$3 \times$ ERE-tat-luc-insulated } \\
\hline & & A & B & \multirow{2}{*}{$\frac{\mathrm{C}}{\text { Testis }}$} & \multirow[t]{2}{*}{ INS1 } & \multirow[t]{2}{*}{ INS2 } & \multirow{2}{*}{$\frac{\text { INS3 }}{\text { Paws }}$} & \multirow[t]{2}{*}{ INS4 } & \multirow[t]{2}{*}{ INS5 } & \multirow[t]{2}{*}{ INS6 } & \multirow{2}{*}{$\frac{\text { INS7 }}{\text { Paws }}$} & \multirow[t]{2}{*}{ INS8 } & \multirow{2}{*}{$\frac{\text { INS9 }}{\text { Testis }}$} \\
\hline & & & & & & & & & & & & & \\
\hline & DES & nd & nd & Testis(+) & - & - & $\begin{array}{l}\text { Liver(+) } \\
\text { Paws }\end{array}$ & - & - & nd & $\begin{array}{l}\text { Liver(+) } \\
\text { Paws }\end{array}$ & - & $\begin{array}{l}\text { Liver(+) } \\
\text { Testis(+) }\end{array}$ \\
\hline \multirow[t]{4}{*}{ Lysates $^{b}$} & Liver & - & - & $+/-$ & - & - & +++ & $+/-$ & $+/-$ & - & +++ & - & + \\
\hline & Testis & - & - & $+/-$ & - & - & ++ & - & - & - & ++ & - & + \\
\hline & Uterus & - & - & - & - & - & + & - & - & - & + & - & - \\
\hline & Brain & - & - & - & - & - & + & - & - & - & + & - & + \\
\hline
\end{tabular}

aOrgans with detectable luciferase activity with the IVIS system. Background: nonexposed animals; DES: exposure to $1000 \mu \mathrm{gg} / \mathrm{kg}$. $(+)$ indicates higher luciferase activity after DES exposure when compared to background levels.

${ }^{b}$ Animals were exposed to $1000 \mu \mathrm{g} / \mathrm{kg}$ DES, and organs were isolated $24 \mathrm{~h}$ after exposure. nd, not determined; +/-, luciferase units after DES exposure 3-10 times background (lysis buffer); +, luciferase units after DES exposure 10-100 times background; ++ , luciferase units after DES exposure 100-10 000 times background; +++, luciferase units after DES exposure $>10000$ times background.

obtaining information of luciferase activation kinetics. In addition, collecting data from the same animal over multiple time points is likely to reduce the statistical variability compared with data from different groups of animals that must be killed at different time points. Dose dependency of induction of luciferase activity was examined in male mice from line INS7. Mice were exposed to increasing doses of either DES or EP. The dose response of induction of luciferase activity in the liver was measured in vivo by the IVIS system. In Fig. 2A, the image of photon activity $8 \mathrm{~h}$ after oil or estrogen exposure is shown. In an elliptical area encompassing the liver, the photon signal was subsequently quantified (Fig. 2B). No luciferase activity was observed after treatment with the solvent control (corn oil). After DES exposure, luciferase activity was measurable at the $10 \mu \mathrm{g} / \mathrm{kg}$ dose and increased further after exposure to 100 and $1000 \mu \mathrm{g} / \mathrm{kg}$. Luciferase activity after EP exposure was measurable only after exposure to 100 and $1000 \mu \mathrm{g} / \mathrm{kg}$. The time-dependent induction of luciferase activity was measured in vivo with the IVIS system (Fig. 3A and B). DES-induced luciferase activity in the liver peaked at the 8-h time point for all concentrations tested (Fig. 3A and B; data not shown). In contrast, luciferase activity induced by EP was maximal $24 \mathrm{~h}$ after exposure (Fig. 3A and B; data not shown). In addition, one dose of $E_{2}(1000 \mu \mathrm{g} / \mathrm{kg})$ was tested with the IVIS system, showing a peak in luciferase activity $8 \mathrm{~h}$ after injection. These data show that it is possible with these transgenic mice in combination with the IVIS system to detect the relative potency of estrogens to activate ERs, as well as the kinetics of this activation.

\section{Tissue-dependent luciferase induction measured in vitro after DES and EP exposure}

After the in vivo measurement of luciferase activity by the IVIS system, the animals were killed, and 13 different organs were isolated for in vitro detection of luciferase activity. Selection of tissues was based on induction of luciferase activity after exposure to DES, as identified during the selection of the transgenic lines. The in vitro measurements showed a considerable variation between the different organs in the basal levels of luciferase activity after oil exposure. In pituitary, esophagus, testis and brain, luciferase activity was relatively high, whereas it was moderate in colon, adrenal, liver, prostate, small intestine and bone, and absent in heart, kidney and lung (Fig. 4). After estrogen exposure, induced luciferase activity was measured in all organs isolated, but induction patterns of luciferase activity were dependent on both the 
A

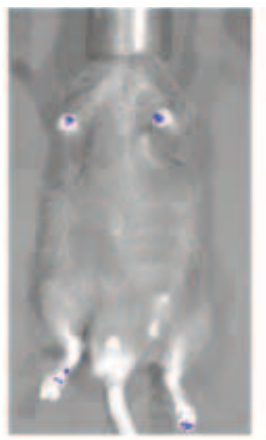

OIL

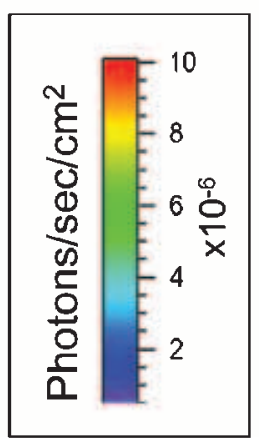

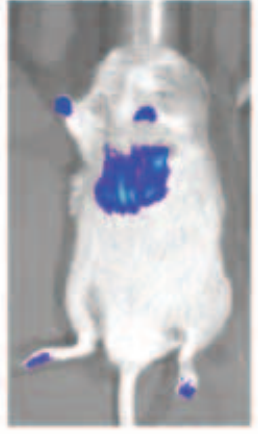

10

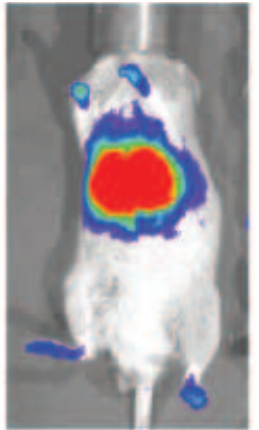

100 $\operatorname{DES}(\mu \mathrm{g} / \mathrm{kg})$

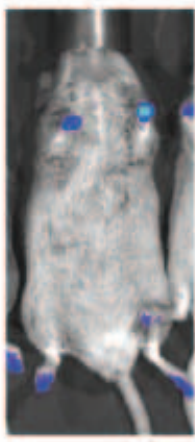

10

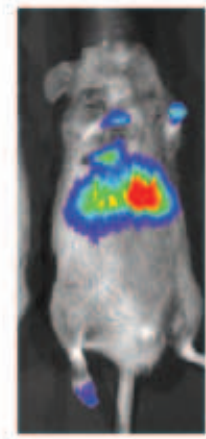

100

$\mathrm{EP}(\mu \mathrm{g} / \mathrm{kg})$

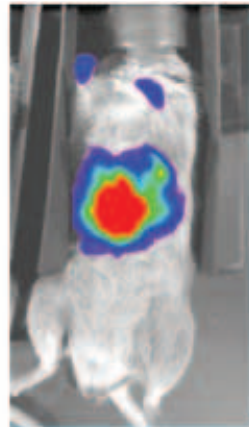

1000

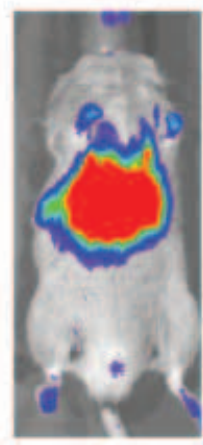

1000

\section{$\mathrm{B}$}

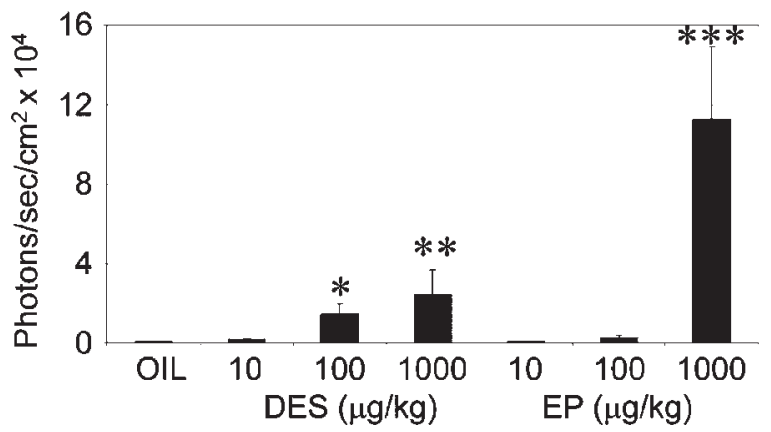

Figure 2 In vivo activation of the estrogen-responsive reporter construct by estrogens. (A) In vivo activation of the estrogen-responsive reporter construct by diethylstilbestrol (DES) and $17 \beta$-estradiol dipropionate (EP) in adult transgenic male mice from line INS7 measured with the IVIS system. Dose-dependent activation of the reporter construct was measured $8 \mathrm{~h}$ after DES or EP exposure

$(10-1000 \mu \mathrm{g} / \mathrm{kg})$. Number of photons produced by the reaction between luciferase and luciferin is depicted in a false-color image superimposed on a video image of the animal. (B) Quantification of the photon signal produced in the liver of the transgenic male mice after DES and EP exposure. Shown is average \pm S.E.M. For oil, DES and EP, $n=5$. Abscissa: dose of DES, EP or solvent (oil) control. Ordinate: photons per $\mathrm{s} / \mathrm{cm}^{2}$ normalized for each animal on $\mathrm{t}=0$, measured in an area encompassing the liver. Significant differences from oil-exposed control, as determined by Kruskal-Wallis analysis followed by Dunn's post-test, is indicated with asterisks; ${ }^{\star} P<0.05,{ }^{\star \star} P<0.01,{ }^{\star \star \star} P<0.001$. 
A
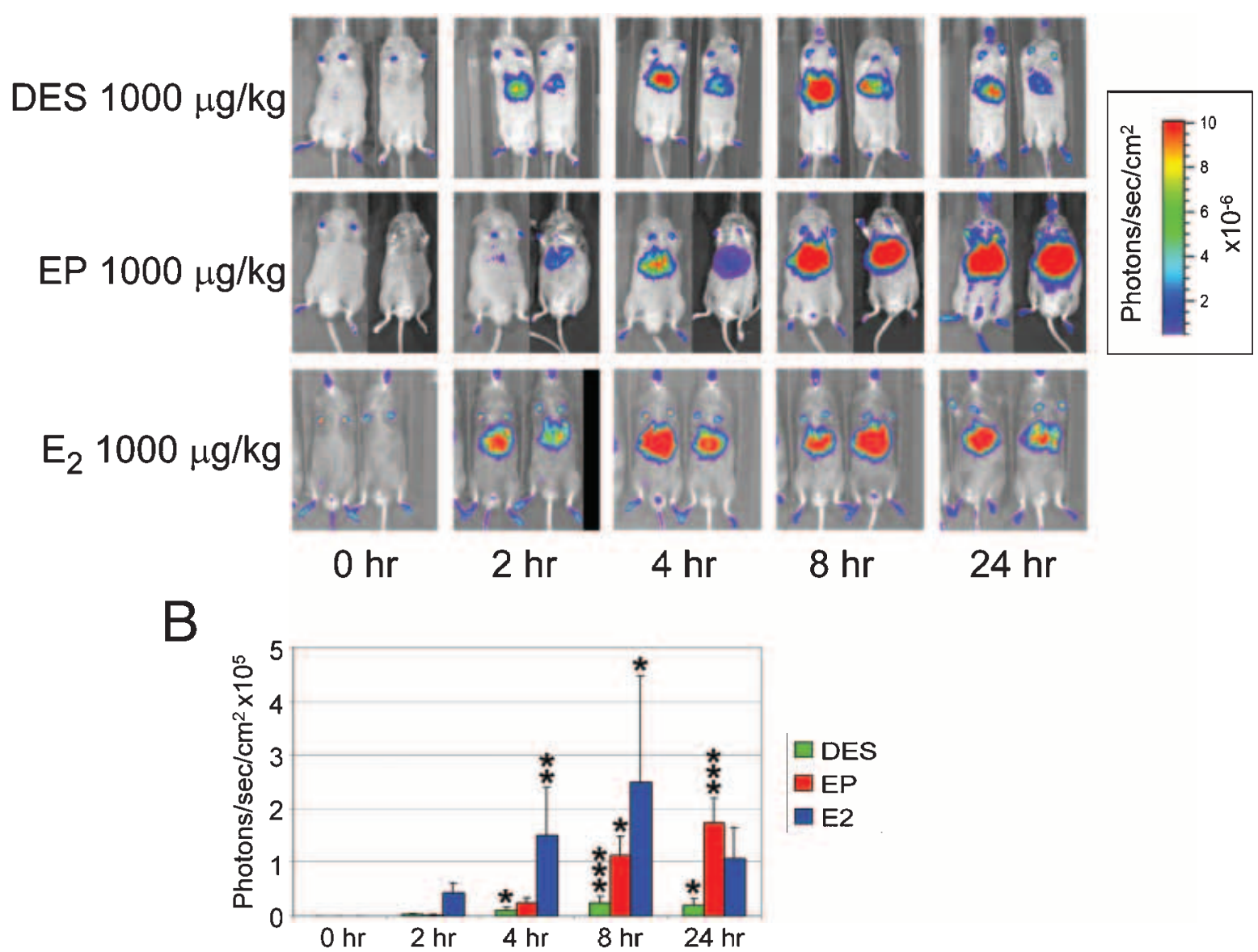

Figure 3 Time course of in vivo activation of the estrogen-responsive reporter construct by estrogens. (A) In vivo activation time course of the estrogen-responsive reporter construct by diethylstilbestrol (DES),

$17 \beta$-estradiol-dipropionate $(\mathrm{EP})$ and $17 \beta$-estradiol $\left(\mathrm{E}_{2}\right)$ in adult transgenic male mice from line INS7 measured with IVIS. After exposure to DES, EP and $E_{2}(1000 \mu \mathrm{g} / \mathrm{kg})$, a time course of activation was measured. The number of photons produced by the reaction between luciferase and luciferin is depicted in a false-color image superimposed on a video image of the animal. (B) Quantification of the photon signal produced in the liver of transgenic male mice at various time points after DES, EP and $E_{2}$ exposure $(1000 \mu \mathrm{g} / \mathrm{kg})$. Shown is average \pm S.E.M. For all, $n=5$. Abscissa: time (h). Ordinate: photons per $\mathrm{s} / \mathrm{cm}^{2}$ normalized for each animal on $\mathrm{t}=0$ measured in an area encompassing the liver. Significant increase in luciferase activity, determined by Friedman test followed by Dunn's post-test, is indicated by asterisks; ${ }^{\star} P<0.05,{ }^{\star \star} P<0.01,{ }^{\star \star \star} P<0.001$.

ligand and the tissue (Fig. 4). The highest induction of luciferase activity was found in bone and kidney; in both organs, it was more than 10000 times induction $24 \mathrm{~h}$ after exposure to $1000 \mu \mathrm{g} / \mathrm{kg} \mathrm{EP}$ (Fig. 4). It is also likely that doses lower than $10 \mu \mathrm{g} / \mathrm{kg}$ would elicit significant induction in organs such as liver, bone, kidney and prostate, where the $10 \mu \mathrm{g} / \mathrm{kg}$ is still highly significant from the oil-exposed control group (Fig. 4). These data show that the reporter mice are responsive to estrogens in a broad range of tissues and organs.

\section{ER dependency of estrogen-induced luciferase activity}

The ER dependency for estrogen-induced luciferase activity was confirmed by exposing mice to the ER antagonist ICI 182,780 (ICI). Luciferase activity induced by endogenous estrogens in all organs except the testis was blocked by ICI exposure (data not shown). Additionally, the ability of ICI to block the luciferase induction in the liver after exposure to DES $(10 \mu \mathrm{g} / \mathrm{kg})$ was examined 


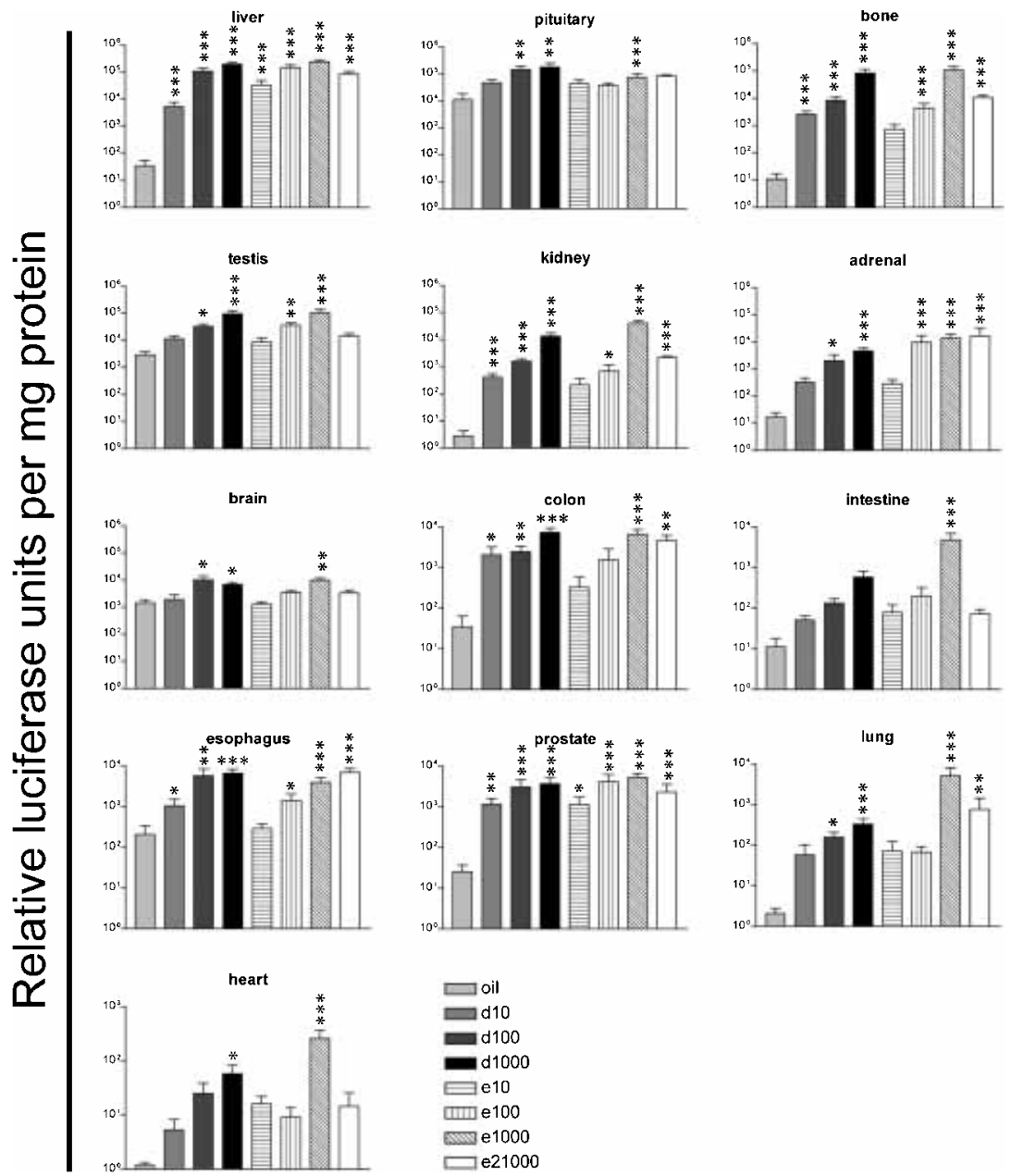

Figure 4 Tissue-specific induction of the estrogen-responsive reporter construct by estrogens. Tissue-specific induction of the estrogen-responsive reporter construct measured in vitro in lysates of different tissues, which were isolated after $24 \mathrm{~h}$ in adult transgenic male mice from line INS7 to various concentrations of diethylstilbestrol (DES), 17 $\beta$-estradiol-dipropionate $(E P)$ and $17 \beta$-estradiol $\left(E_{2}\right)$. Shown are the relative luciferase units (RLU) per $\mathrm{mg}$ protein induced by exposure to oil, DES, EP and $\mathrm{E}_{2}$. Average \pm S.E.M. of the RLUs is shown. For all groups, $n=7$, except for EP10 and 1000, for which $n=8$. Significant differences from oil-exposed control as determined by ANOVA followed by Tukey's post-test are indicated by asterisks; ${ }^{\star} P<0.05,{ }^{* *} P<0.01,{ }^{* * \star} P<0.001$. Note scale differences. Abscissa: oil or dose of DES, EP and $E_{2}$. Ordinate: RLU per mg protein.

with the IVIS system (Fig. 5A and B). A dose of $250 \mu \mathrm{g} / \mathrm{kg}$ ICI was not sufficient to block the DES-induced luciferase activity completely in all animals, but one of $2500 \mu \mathrm{g} / \mathrm{kg}$ ICI was. These data were confirmed by measuring luciferase activity in liver lysates (Fig. 5B). These results show that the ability of ICI to block both endogenous and DES-activated luciferase activity is due to activated ERs.

\section{Discussion}

Transgenic mice carrying an estrogen-responsive reporter construct coupled to luciferase were generated to study direct activation of ERs in vivo. With this in vivo model, it is possible to assess efficiently the ability of different compounds to activate ERs in a broad range of tissues. 

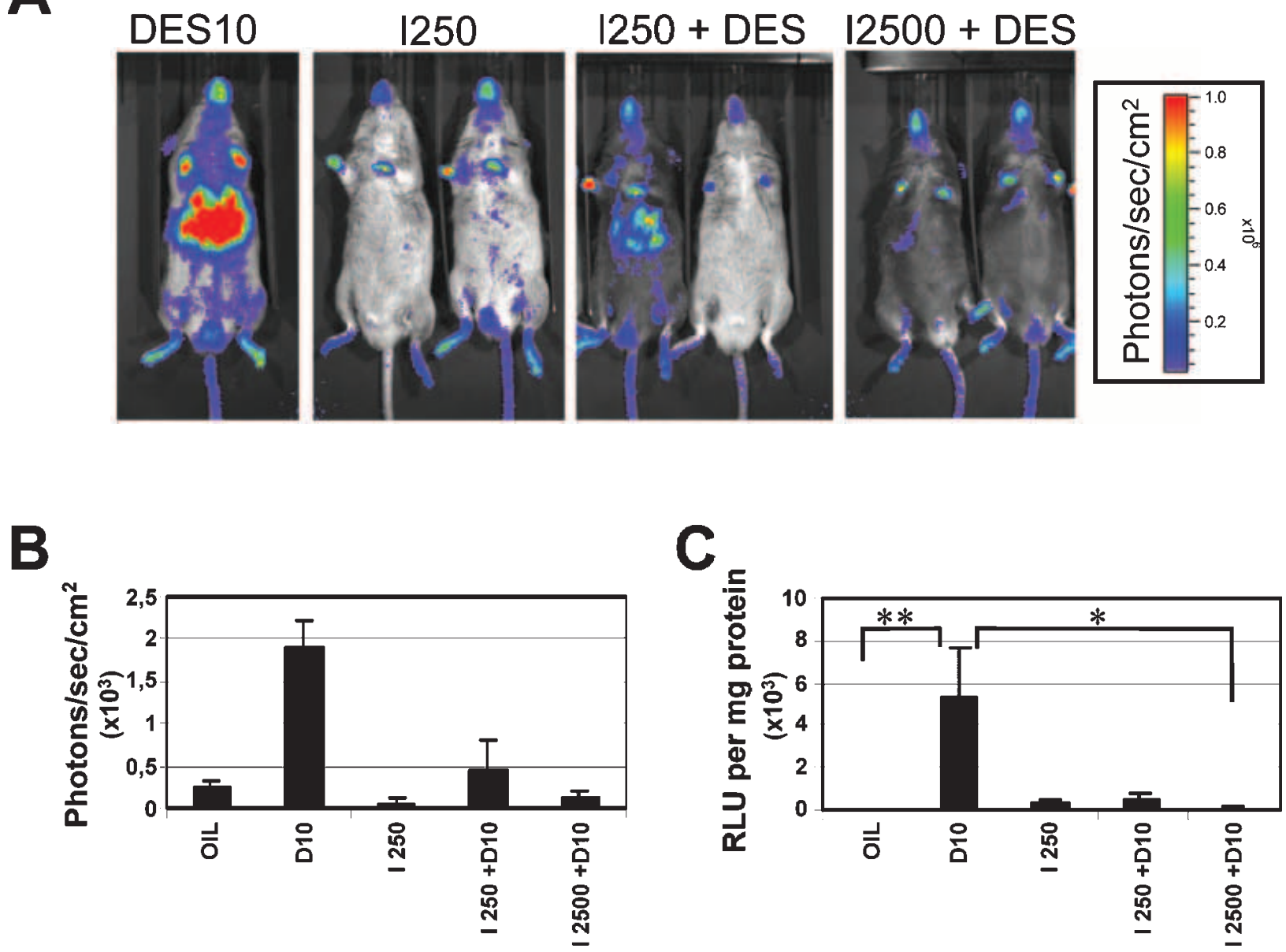

Figure 5 Inhibition of diethylstilbestrol (DES)-induced reporter expression by ICI 182,780 (ICI). (A) Inhibition of DES-induced in vivo activation of the estrogen-responsive reporter construct by the antiestrogen ICl, as measured with IVIS in adult transgenic male mice from line INS7. Pretreatment with ICI $(2500 \mu \mathrm{g} / \mathrm{kg})$ for 60 min resulted in a complete block of DES activation. Photon number produced by the reaction between luciferase and luciferin is depicted in a false-color image superimposed on a video image of the animal. (B) Quantification of the photon signal produced in livers of transgenic male mice at $8 \mathrm{~h}$ after hormone exposure. Shown is average \pm S.E.M. For the IVIS data, $n=2-5$. Abscissa: hormone exposure in $\mu \mathrm{g} / \mathrm{kg}$. Ordinate: photons per $\mathrm{s} / \mathrm{cm}^{2}$ normalized for each animal on $\mathrm{t}=\mathrm{o}$ measured in an area encompassing the liver. (C) Quantification of luciferase measured in vitro in liver lysates of transgenic male mice at $24 \mathrm{~h}$ after hormone exposure. Shown is average \pm S.E.M.; $n=2-5$. Abscissa: hormone exposure in $\mu \mathrm{g} / \mathrm{kg}$. Ordinate in LUMAC: relative luciferase units per mg protein. $\mathrm{I}=\mathrm{ICl} 182,780 ; \mathrm{D}=\mathrm{DES}$. Significant differences from control exposed to DES $10 \mu \mathrm{g} / \mathrm{kg}$, as determined by Kruskal-Wallis analysis followed by Dunn's post-test, is indicated by asterisks; ${ }^{\star} P<0.05,{ }^{* \star} P<0.01$.

After in vitro characterization of the constructs, transgenic lines were generated with these constructs. With the noninsulated and insulated construct, one and five expressing lines were obtained respectively. The level of expression in the noninsulated line was similar to the two weakest insulated lines. It is possible that the higher level of luciferase activity after in vitro stimulation of the insulated construct contributed to the ability to detect expression of luciferase in the lines with this construct. Insulator sequences are believed to prevent possible integration effects, such as silencing or unregulated expression of the transgenic construct (Wang et al. 1997). Whether the use of insulators has played a role in the higher number of expressing lines, the more ubiquitous expression 
and high inducibility in these lines cannot be directly assessed due to the different number of founders obtained with the two constructs.

Both DES and EP induced luciferase activity dose-dependently when measured in vivo with the IVIS, as well as ex vivo in tissue extracts. The results of comparing maximal luciferase activity in isolated tissues showed that EP often induced higher levels than the same dose of DES $24 \mathrm{~h}$ after exposure. However, as DES induces luciferase activity at lower doses than EP and the peak of DES-induced luciferase activity is earlier than that of EP, it is difficult to conclude which hormone is to be considered more potent in our in vivo model. In vitro studies have shown DES to be as potent as $\mathrm{E}_{2}$ (Kuiper et al. 1998) and as EP (our unpublished data). In a 3-day uterotrophic assay, DES was slightly more potent than $\mathrm{E}_{2}$ (Jefferson et al. 2002). No reports comparing target gene expression in vivo after DES and $\mathrm{E}_{2}$ exposure are available for mice. Differences in induction of a target gene between $\mathrm{E}_{2}$ and DES could be explained by the fact that coactivators and corepressors are differentially expressed. Moreover, some cofactors might have a better interaction with DES-bound ER and others with $\mathrm{E}_{2}$-bound ER (Pennie et al. 1998).

The kinetic data obtained with the IVIS system showed that the transactivation activity of DES peaked $8 \mathrm{~h}$ after exposure for all doses tested. In adult rats treated with ${ }^{14} \mathrm{C}$-DES, plasma values were found to peak at $4 \mathrm{~h}$ (Bengtsson \& Ullberg 1963). In the plasma of pregnant mice exposed to ${ }^{14} \mathrm{C}$-DES, a rapid disappearance of DES was found with a subsequent peak of DES conjugates after $8 \mathrm{~h}$ (McLachlan 1977), consistent with the peak we observed in luciferase activity in the transgenic mice. Exposure of the transgenic mice to $\mathrm{E}_{2}$ resulted in a luciferase activity peak after $8 \mathrm{~h}$. Similarly, target gene activity in transgenic pMAR mice peaked in liver and bone $6 \mathrm{~h}$ after $\mathrm{E}_{2}$ exposure (Ciana et al. 2001, 2003). With respect to EP, its transactivation activity was highest $24 \mathrm{~h}$ after exposure, as shown with the IVIS system. EP induced a peak in luciferase activity later than $\mathrm{E}_{2}$, consistent with the view that the added propionate groups must first be removed before the active $\mathrm{E}_{2}$ is available.

Background levels of luciferase activity varied extensively between different organs studied. This could be due to a difference in the level of endogenous estrogens in the tissues. Local production of estrogens is a likely reason for the high background activity observed in the testis (Carreau 2001). High background levels of luciferase activity in brain, pituitary and testis could possibly also reflect ER expression, which is high in these tissues (Kuiper et al. 1997). In all tissues except the testis, background activity was blocked after treatment with ER antagonist ICI 182,780. The reason for the lack of reduction of luciferase activity in the testis might be due to the inability of ICI 182,780 to pass the blood-testis barrier efficiently (Setchell \& Main 1978).

Sensitivity to estrogen exposure varied for the various tissues. Organs showing a high fold induction of luciferase after estrogen exposure include bone, adrenal, liver, prostate, kidney, colon and lung. Some of these organs were also found to be relatively responsive in pMAR mice, although the fold induction was lower than in INS7 mice (Ciana et al. 2001, Di Lorenzo et al. 2002), while adrenal and colon tissue was not described. In ERIN mice, high inducibility was found in the kidney and slight induction in the adrenal gland, but no induction was found in lung, while bone, prostate and colon were not examined (Nagel et al. 2001). In ERE-EGFP reporter mice, $\mathrm{E}_{2}$-regulated induction of the reporter was found in pituitary, ovary, uterus, adrenal gland and gonadal fat pad (Toda et al. 2003). The use of male mice versus ovariectomized female mice (Ciana et al. 2001, Nagel et al. 2001) or aromatase knockout females (Toda et al. 2003) could explain the lower induction observed in pMAR and ERIN mice, because low estradiol levels might still be present. However, this does not explain the low induction in the ERE-EGFP mice with aromatase knockout females, which have no circulating estradiol; here the use of EGFP might have influenced the inductions measured. In addition, the use of a very minimal TATA promoter in the present study, instead of the TK promoter used for the ERIN (Nagel et al. 2001) and pMAR (Ciana et al. 2001) mice or the hsp68-promoter for the ERE-EGFP mice (Toda et al. 2003), could have resulted in lower background activation and therefore higher fold inductions in the INS7 mice. In brain and testis of INS7 mice, the fold induction after estrogen exposure was relatively small, suggesting that background levels were present due to local activity of estrogens. In general, in organs where estrogen signaling plays an important role, tight 
feedback mechanisms might be in place, keeping the effects of exogenously administered estrogens within certain limits, which in the present context means low induction of luciferase activity. In contrast, in organs with low endogenous estrogen signaling, in addition to lower background levels, the regulatory mechanisms may be less tight and therefore high luciferase activity can be induced already after exposure to low doses. Other mechanisms possibly involved are downregulation of ERs and/or coactivators, and upregulation of corepressors.

Our in vivo model for detecting estrogenic activity is a promising tool for various lines of research. Tissue-specific action of ER agonists and antagonists, including $\mathrm{ER} \alpha / \mathrm{ER} \beta$ specific ligands, environmental estrogens and SERMs, can be assessed. In addition, in combination with the IVIS imaging system, this in vivo model will be an effective means for assessing kinetics of receptor-mediated gene activation. Currently, experiments assessing placental transfer and activation of embryonal ERs by classical estrogens and environmental estrogens are carried out with this model.

\section{Acknowledgements}

We thank the staff of the animal facility of Hubrecht Laboratory for their dedication, and Dr G. Felsenfeld for providing us with the insulator plasmid. This study has been carried out with financial support from the Commission of the European Communities, specific RTD program: 'Quality of Life and Management of Living Resources' (QLK4-2000-00305); 'The Impact of Developmental Exposure to Weak (Environmental) Estrogens on the Incidence of Diseases in Target Organs Later in Life'. This paper does not necessarily reflect the views of the Commission, and in no way anticipates its future policy in this area.

\section{References}

Andersen HR, Andersson AM, Arnold SF, Autrup H, Barfoed M, Beresford NA, Bjerregaard P, Christiansen LB, Gissel B, Hummel $\mathrm{R}$ et al. 1999 Comparison of short-term estrogenicity tests for identification of hormone-disrupting chemicals. Enviromental Health Perspectives 107 Suppl 1 89-108.

Ashby J, Odum J, Paton D, Lefevre PA, Beresford N \& Sumpter JP 2000 Re-evaluation of the first synthetic estrogen,

1-keto-1,2,3,4-tetrahydrophenanthrene, and bisphenol A, using both the ovariectomised rat model used in 1933 and additional assays. Toxicology Letters 115 231-238.

Bengtsson G \& Ullberg S 1963 The auroradiographic distribution pattern after administration of diethylstilboestrol compared with that of natural oestrogens. Acta Endocrinologica 43 561-570.

Carreau S 2001 Germ cells: a new source of estrogens in the male gonad. Molecular and Cellular Endocrinology 178 65-72.

Chung JH, Whiteley M \& Felsenfeld G 1993 A 5' element of the chicken beta-globin domain serves as an insulator in human erythroid cells and protects against position effect in Drosophila. Cell 74 505-514.

Ciana P, Di Luccio G, Belcredito S, Pollio G, Vegeto E, Tatangelo L, Tiveron C \& Maggi A 2001 Engineering of a mouse for the in vivo profiling of estrogen receptor activity. Molecular Endocrinology 15 1104-1113.

Ciana P, Raviscioni M, Mussi P, Vegeto E, Que I, Parker MG, Lowik C \& Maggi A 2003 In vivo imaging of transcriptionally active estrogen receptors. Nature Medicine 9 82-86.

Diel P, Schulz T, Smolnikar K, Strunck E, Vollmer G \& Michna H 2000 Ability of xeno- and phytoestrogens to modulate expression of estrogen-sensitive genes in rat uterus: estrogenicity profiles and uterotropic activity. Fournal of Steroid Biochemistry and Molecular Biology 73 1-10.

Di Lorenzo D, Villa R, Biasiotto G, Belloli S, Ruggeri G, Albertini A, Apostoli P, Raviscioni M, Ciana P \& Maggi A 2002 Isomer-specific activity of dichlorodyphenyltrichloroethane with estrogen receptor in adult and suckling estrogen reporter mice. Endocrinology $1434544-4551$.

Farhat MY, Lavigne MC \& Ramwell PW 1996 The vascular protective effects of estrogen. FASEB Fournal 10 615-624.

Grese TA, Sluka JP, Bryant HU, Cullinan GJ, Glasebrook AL, Jones CD, Matsumoto K, Palkowitz AD, Sato M, Termine JD, Winter MA, Yang NN \& Dodge JA 1997 Molecular determinants of tissue selectivity in estrogen receptor modulators. PNAS 94 14105-14110.

Harrington WR, Sheng S, Barnett DH, Petz LN, Katzenellenbogen JA \& Katzenellenbogen BS 2003 Activities of estrogen receptor alpha- and beta-selective ligands at diverse estrogen responsive gene sites mediating transactivation or transrepression. Molecular and Cellular Endocrinology 206 13-22.

Iafrati MD, Karas RH, Aronovitz M, Kim S, Sullivan TRJ, Lubahn DB, O'Donnell TFJ, Korach KS \& Mendelsohn ME 1997 Estrogen inhibits the vascular injury response in estrogen receptor alpha-deficient mice. Nature Medicine 3 545-548.

Jefferson WN, Padilla-Banks E, Clark G \& Newbold RR 2002 Assessing estrogenic activity of phytochemicals using transcriptional activation and immature mouse uterotrophic responses. Fournal of Chromatography B 777 179-189.

Khurana S, Ranmal S \& Ben-Jonathan N 2000 Exposure of newborn male and female rats to environmental estrogens: delayed and sustained hyperprolactinemia and alterations in estrogen receptor expression. Endocrinology $1414512-4517$.

Korach KS, Migliaccio S \& Davis VL 1994 Estrogens. In Principles of Pharmacology - Basic Concepts and Clinical Applications, pp 809-825. Ed PL Munson. New York: Chapman and Hall.

Kuiper GG, Carlsson B, Grandien K, Enmark E, Haggblad J, Nilsson S \& Gustafsson JA 1997 Comparison of the ligand binding specificity and transcript tissue distribution of estrogen receptors alpha and beta. Endocrinology 138 863-870.

Kuiper GG, Lemmen JG, Carlsson B, Corton JC, Safe SH, van der Saag PT, van der Burg B \& Gustafsson JA 1998 Interaction of estrogenic chemicals and phytoestrogens with estrogen receptor beta. Endocrinology 139 4252-4263.

LeBlanc GA, Bain LJ \& Wilson VS 1997 Pesticides: multiple mechanisms of demasculinization. Molecular and Cellular Endocrinology 126 1-5. 
Legler J, van den Brink CE, Brouwer A, Murk AJ, van der Saag PT, Vethaak AD \& van der Burg B 1999 Development of a stably transfected estrogen receptor-mediated luciferase reporter gene assay in the human T47D breast cancer cell line. Toxicological Sciences 48 55-66.

Legler J, Broekhof JLM, Brouwer A, Lanser PH, Murk AJ, van der Saag PT, Wester P, Zivkovic D \& van Der B 2000 A novel in vivo bioassay for (xeno-)estrogens using transgenic zebrafish. Environmental Science and Technology 34 4439-4444.

McLachlan JA 1977 Prenatal exposure to diethylstilbestrol in mice: toxicological studies. Fournal of Toxicology and Environmental Health $\mathbf{2}$ 527-537.

Nagel SC, Hagelbarger JL \& McDonnell DP 2001 Development of an ER action indicator mouse for the study of estrogens, selective ER modulators (SERMs), and xenobiotics. Endocrinology 142 4721-4728.

Pennie WD, Aldridge TC \& Brooks AN 1998 Differential activation by xenoestrogens of ER alpha and ER beta when linked to different response elements. Fournal of Endocrinology 158 R11-R14.

Potts W, Tucker D, Wood H \& Martin C 2000 Chicken beta-globin 5 'HS4 insulators function to reduce variability in transgenic founder mice. Biochemical and Biophysical Research Communications 273 $1015-1018$.
Schlumpf M, Cotton B, Conscience M, Haller V, Steinmann B \& Lichtensteiger W 2001 In vitro and in vivo estrogenicity of UV screens. Environmental Health Perspectives 109 239-244.

Setchell B \& Main S 1978 Drugs and the blood-testis barrier. Environmental Health Perspectives 24 61-64.

Shang Y \& Brown M 2002 Molecular determinants for the tissue specificity of SERMs. Science 295 2465-2468.

Toda K, Okada Y, Zubair M, Morohashi KI, Saibara T \& Okada T 2003 Aromatase-knockout mouse carrying an estrogen-inducible enhanced green fluorescent protein gene facilitates detection of estrogen actions in vivo. Endocrinology 145 1880-1888.

Turner RT, Riggs BL \& Spelsberg TC 1994 Skeletal effects of estrogen. Endocrine Reviews 15 275-300.

Wang Y, DeMayo FJ, Tsai SY \& O’Malley BW 1997 Ligand-inducible and liver-specific target gene expression in transgenic mice. Nature Biotechnology 15 239-243.

\author{
Received 20 February 2004 \\ Accepted 10 March 2004 \\ Made available online as an \\ Accepted Preprint 18 March 2004
}

